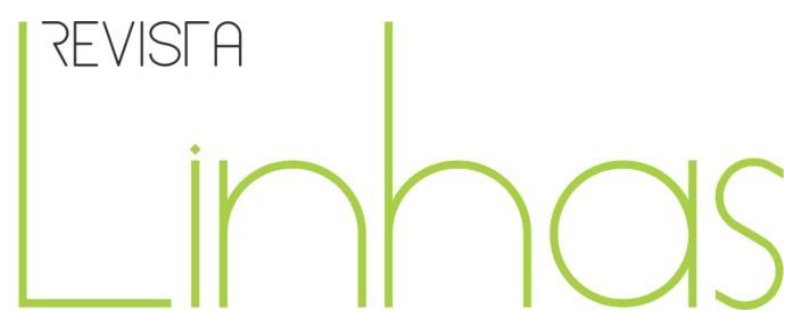

\title{
Das inovações no ensino ao ensino inovador: a percepção dos estudantes na complexidade do sistema didático ${ }^{1}$
}

\begin{abstract}
Resumo
O presente estudo objetivou investigar as percepções dos estudantes universitários sobre os elementos estruturantes das inovações no ensino e as possibilidades de organização do ensino inovador. A pesquisa, de natureza qualitativa, do tipo exploratório-descritiva, foi realizada com a participação de 40 estudantes dos cursos de licenciatura de uma universidade pública federal do sul do estado do Rio Grande do Sul, Brasil. Os dados foram produzidos de forma voluntária, por meio de um questionário, com questões fechadas e abertas. Estas informações foram estudadas por meio da análise de conteúdo, estruturada a partir das etapas: pré-análise de exploração do material e tratamento dos resultados. Em nosso estudo, foram mapeadas nove categorias referentes à percepção dos estudantes acerca das ações docentes inovadoras no ensino: teoria e prática, domínio de conteúdo, ensino de procedimentos, diferentes metodologias, contextualização, problematização, interdisciplinaridade, pesquisa e relação interpessoal. Compreendemos que as possibilidades de um ensino inovador vinculam-se à compreensão deste como um sistema didático complexo, não linear. As inovações no ensino não representam uma ruptura epistemológica, mas podem redimensionar um fazer diferente, que pode ou não proporcionar alterações na ação docente. Com isto, concluímos que as inovações pontuais no ensino não garantem uma transição paradigmática, mas anunciam as possibilidades de um ensino inovador.
\end{abstract}

Palavras-chave: Ensino Superior. Efeito das Inovações Tecnológicas. Inovações Educacionais.

\section{Para citar este artigo:}

BORGES, Daniele Simões; TAUCHEN, Gionara. Das inovações no ensino ao ensino inovador: a percepção dos estudantes na complexidade do sistema didático. Revista Linhas. Florianópolis, v. 19, n. 39, p. 167-190, jan./abr. 2018.

DOI: $10.5965 / 1984723819392018167$

http://dx.doi.org/10.5965/1984723819392018167

\footnotetext{
${ }^{1}$ Esta pesquisa recebeu financiamento da Coordenação de Aperfeiçoamento de Pessoal de Nível Superior CAPES.
}

Daniele Simões Borges

Universidade Federal do Rio

Grande - FURG - Rio Grande/RS Brasil

daniele.uab@gmail.com

\section{Gionara Tauchen}

Universidade Federal do Rio Grande - FURG - Rio Grande/RS Brasil

giotauchen@gmail.com 


\title{
From innovations in teaching to innovative teaching: the students' perceptions of the complexity of the educational system
}

\begin{abstract}
The present study aimed to investigate the perceptions of university students about the structural elements of innovations in teaching and opportunities for innovative teaching organization. The research was qualitative, exploratory and descriptive, was held with the participation of 40 different graduate students from a public university in southern federal state of Rio Grande do Sul, Brazil. Students announced as innovations in teaching, among other elements, the different methodologies, contextualization, problematization, interdisciplinarity, teaching procedures, the domain of conceptual contents, interpersonal relations, research and theory- practice relationship. We concluded that the chances of an innovative education are linked to the understanding of this system as an educational complex, non-linear.
\end{abstract}

Keywords: Higher education. Effect of Technological Innovations. Educational Innovations. 


\section{Introdução}

Os entendimentos sobre inovação navegam por cenários peculiares e arriscados. Peculiares por guardarem uma polissemia de significados, expressando a temporalidade, a historicidade e os contextos particulares, em que são gestadas suas condições de possibilidade; arriscados porque podem assumir diferentes conotações e ações, promovendo ou reprimindo os processos de melhorias no ensino. Observamos, em muitos anúncios, o uso do termo vinculado à reforma, à modernização e à mudança. No entanto, Carbonell (2002) adverte que a inovação não pode ser vinculada diretamente à renovação e à mudança pedagógica, pois "[...] a reforma não é sinônimo de mudança, melhoria ou inovação. Estas podem provocá-la, mas também paralisá-la e sufocá-la” (CARBONELL, p. 20). Uma inovação nem sempre será sinônimo de mudança, pois pode ser passageira e pontual; do mesmo modo, a reforma. Para a inovação produzi-la, primeiro tem que desestabilizar as relações organizacionais do sistema educativo, ou seja, não é uma ação neutra, mas intencional, uma vez que pode modificar em caráter macro e micro o sistema educativo "[...] implicando alterações em seus objetivos, na organização e funcionamento das instituições escolares (SILVA, 2011, p. 59)”. O conceito de reforma tem um caráter gradual, atuando, geralmente, na episteme e no contexto educativo, constituindo assim, uma mudança instituída (FARIAS, 2006).

Os primeiros estudos sobre inovação decorrem do campo econômico, sendo interpretados por Christensen, Horn \& Johnson (2012, p. 216) como “[...] fonte de soluções e de força", visando a melhoria e o aperfeiçoamento contínuo do sistema, podendo sustentar a evolução social. Nesse campo, os autores distinguem dois tipos de inovações: as sustentadas e as disruptivas. As inovações sustentadas ocorrem dentro do sistema, visando uma melhoria gradual. Ou seja, podem ser mecanismos de autocorreção, pois, por mais rígidos que esses sejam, não permanecerão para sempre sem um desafio. Na década de 90, por exemplo, os professores que atuavam nas escolas básicas sentiram sua atividade profissional ameaçada pela chegada dos computadores. Ouvia-se que esses substituiriam o trabalho do professor, pois violavam as expectativas do seu paradigma de ensino. Contudo, aos poucos, as novas tecnologias foram convertidas em fator de inovação e qualificação das práticas educativas. Assim, entendemos que as inovações sustentadas podem promover a inovação disruptiva que "[...] não estabelece raízes por 
meio de um ataque frontal ao sistema. Pelo contrário, ela deve contornar o sistema ou tratar de infiltrá-lo. É dessa forma que a disrupção orienta disponibilidade, acesso, capacitação e responsabilidade" (CHRISTENSEN, HORN, JOHNSON, 2012, p. 211). Assim, os autores associam às inovações disruptivas o conceito de inovação radical e que, para Cunha (2005), significa uma mudança de paradigma.

As inovações sustentadas aproximam-se do conceito de inovação incremental, pois produzem respostas e promovem melhorias nos processos. Podemos citar, como exemplo, a incorporação de diários de aprendizagem ao sistema de avaliação proposto por um professor. A incorporação de um novo instrumento não assegura uma mudança na sua concepção de aprendizagem, de ensino e de avaliação. Contudo, pode produzir melhorias na aprendizagem, como a qualificação da escrita dos alunos e a ampliação das compreensões sobre a ação, promovendo mudanças no modo de pensar e agir, potencializando outras inovações e, até mesmo, uma mudança em suas concepções ou paradigmas.

No âmbito do ensino, Hassenforder (1974) vincula a inovação ao desenvolvimento das ciências da educação e da sociedade, e afirma que a inovação não cabe à generalização, uma vez que corresponde às necessidades determinadas em um contexto relativo. Com isso, o autor assegura a tese de que a inovação implica na diversidade e é constituída por diferentes expressões, apontando-a como um fenômeno social, cultural e contextual, dependente do seu contexto.

No campo do ensino de ciências, Krasilchik (1980) realizou as primeiras análises sobre o tema, discutindo os movimentos históricos e as reformas, das políticas às salas de aula, que tinham como objetivo melhorar o ensino. De modo geral, tem-se concordado com Carbonell (2002, p. 19), que define as inovações no ensino como "um conjunto de intervenções, decisões e processos, com certo grau de intencionalidade e sistematização, que tratam de modificar atitudes, ideias, culturas, conteúdos, modelos e práticas pedagógicas". Farias (2006) complementa que uma das condições essenciais para se produzir uma inovação está em “[...] incorporar algo que até então não fazia parte da unidade de referência, alterando-a" (FARIAS, 2006, p. 52). Portanto, nessa perspectiva, a inovação tem a pretensão de suscitar mudanças e, por isso, “[...] é conduzida com a finalidade de incorporar algo novo que resulte em melhoria no âmbito da instituição 
escolar, em suas estruturas e processos, visando ao êxito de sua função social" ( FARIAS, 2006, p. 55).

Compreendemos que a aula é um dos lugares estratégicos, no qual o professor cria e recria sua ação docente e que a universidade pode tornar-se um território propício à inovação e à criação de diferentes formas de ensinar e aprender pela diversidade que a constitui e a integra. Chegamos, assim, à ideia principal a esse respeito que, conforme destaca Zabalza (2004, p. 189), consiste em “[...] conceber a universidade como 'instituição de aprendizagem' frente à ideia mais geral de entendê-la como instituição de ensino". Essa consideração nos remete a um conjunto de preocupações essenciais para quem desenvolve o trabalho formativo: Quais os processos e as estratégias por meio dos quais os estudantes chegam à aprendizagem? Quais as percepções dos estudantes sobre as condições de aprendizagem? Como as relações que estabelecem com o conhecimento são mediadas pelo professor? Quais ações que reconhecem como expressões das inovações no ensino? Como as inovações no ensino podem promover um ensino inovador? Que princípios epistemológicos podem sustentar a organização de um ensino inovador?

Com base nestes questionamentos, propusemo-nos a investigar os elementos de inovação no ensino, compreendida como toda ação educativa que visa alterar, aperfeiçoar e qualificar o feito nas ações educativas. Balizamos nosso estudo no pensamento complexo, buscando "[...] enfrentar o emaranhado (o jogo infinito das interretroações, a solidariedade dos fenômenos entre eles, a bruma, a incerteza, a contradição)" (MORIN, 2007, p. 14), ou seja, pensamos a inovação a partir da sua complexidade educativa.

\section{Percurso metodológico}

O estudo caracteriza-se como pesquisa qualitativa, de cunho exploratóriodescritivo (TRIVIÑOS, 1987), pois teve por objetivo investigar as compreensões e as relações educativas vivenciadas pelos estudantes universitários que podem "contribuir para instaurar e/ou ampliar o debate sobre a aula no espaço da universidade [...]" (SILVA, 2011, p. 30). 
Os dados foram coletados de forma voluntária, por meio de um questionário, com questões fechadas e abertas, totalizando a participação de 40 estudantes do último ano dos cursos presenciais de licenciatura em Ciências Biológicas (10), Física (10), Química (10) e Pedagogia (10), de uma universidade federal do sul do estado do Rio Grande do Sul, Brasil. Para a coleta dos dados, entramos em contato com os docentes que atuam no último ano dos referidos cursos, solicitando a colaboração para a aplicação dos questionários em situações de aula, ou seja, participaram somente os estudantes que estavam presentes em aula no dia do desenvolvimento da pesquisa. Devido à variação do número de estudantes, entre os cursos, realizamos a seleção de uma amostra aleatória simples de 10 questionários, visando a representação equitativa dos dados.

A opção por estes cursos de licenciatura vincula-se a nossa intencionalidade de ampliar as compreensões sobre a temática no campo das ciências da natureza. Nesta perspectiva, incluímos o curso de Pedagogia, por considerar que este contempla, na matriz curricular da formação inicial, bem como na prática profissional dos egressos, o ensino de ciências. A investigação junto aos estudantes do último ano da graduação, por sua vez, foi por considerar que estes já construíram entendimentos sobre a temática em estudo, dado o seu conhecimento experiencial e curricular sobre os processos de ensino e aprendizagem.

Os dados coletados foram estudados por meio da Análise de Conteúdo (BARDIN, 1977), estruturada a partir das etapas: pré-análise de exploração do material e tratamento dos resultados. A pré-análise ocorreu na compilação dos dados da pesquisa e na leitura flutuante dos questionários. A segunda fase consistiu na realização de operações de codificação, em que identificamos cada um dos questionários por letras, correspondentes às iniciais dos cursos ( $\mathrm{B}, \mathrm{P}, \mathrm{Q}$ e $\mathrm{F}$ ), e números na sequência de 1 a 87 . Em virtude da disparidade do número de estudantes entre os cursos, trabalhamos com o procedimento de amostragem probabilística visando equalizar os dados. Por meio de sorteio aleatório foi selecionada uma amostragem de 10 questionários para cada curso. Após o mapeamento e sorteio dos questionários, procedemos às unidades de análise de registro e de contexto. Desta etapa, emergiram as categorias que expressam o conjunto das ações inovadoras no ensino, analisadas na terceira fase, que consistiu na discussão dos resultados considerados significativos. 


\section{Análise dos dados: reflexões e discussões}

Percebemos que o inovar, na compreensão dos estudantes, assume uma rede de descobertas, de afetos, de saberes, de significações e de diferentes formas de ensinar e aprender no ensino universitário, como analisaremos na sequência. Em nosso estudo, mapeadas nove categorias referentes à percepção dos estudantes acerca das ações docentes inovadoras no ensino: teoria e prática, domínio de conteúdo, ensino de procedimentos, diferentes metodologias, contextualização, problematização, interdisciplinaridade, pesquisa e relação interpessoal.

Nos cursos de licenciatura, das nossas instituições de Educação Superior, é tradicional presenciarmos primeiro, uma formação “teórica” e, depois, a "prática”. Esta última, em grande parte, diretamente vinculada aos estágios supervisionados (PIMENTA 1999). Tal cenário não conduz ao preparo suficiente para a atuação docente, uma vez que dissipa a formação, desconsiderando que o próprio exercício de teorizar já é uma prática. Para Pimenta (1999, p. 16), essa desarticulação entre teoria e prática

[...] tem demonstrado que os cursos de formação, ao desenvolverem um currículo formal com conteúdos e atividades de estágio distanciadas da realidade das escolas, numa perspectiva burocrática e cartorial que não dá conta de captar as contradições presentes na prática social de educar, pouco tem contribuído para gestar uma nova identidade profissional.

Compreende-se, com estas reflexões, a perspectiva dos estudantes que apontaram como anúncio inovador a articulação teoria e prática. Assim, partimos do pressuposto de que, ao ser considerado inovador, é porque ainda não há uma integração efetiva no conjunto das experiências formativas desenvolvidas por meio do ensino universitário. Logo, a articulação teoria e prática ainda é um desafio epistemológico e histórico a ser superado. Santos e Sommerman (2009, p. 26) consideram que essa dicotomia e fragmentação é decorrente do tratamento mecânico estabelecido com o conhecimento:

Os professores dedicam-se a explicações exaustivas em definições, conceitos, fórmulas, e fazem uso da linguagem voltada para a 
racionalidade tecnocientífica. A fragmentação traz como consequência a idéia de neutralidade e objetividade do conhecimento. Com esse viés, o conhecimento referido em sala de aula perde sentido existencial ao não trabalhar a relação com o todo e com o sujeito do processo cognitivo.

Por isto, o professor que expressa essa indissociabilidade contribui para a construção de novas representações e é percebido pelo estudante como expressão de uma inovação no ensino, conforme expressam as afirmações: "Articula os conteúdos com experiências práticas, além de valer-se de resumos, esquemas, aulas que articulem conhecimento e ação" (P4); “proporciona práticas, através de seminários, trocas, vivências com o assunto estudado x práticas" (P18).

Percebemos que os estudantes reconhecem o docente que faz uso de diferentes estratégias didáticas, objetivando esta articulação. Neste sentido, podemos ponderar que a sala de aula do professor, que não dissocia teoria e prática, constitui-se como um "[...] cenário de encontro e das múltiplas possibilidades que professores e alunos têm de fazer dele um tempo de aprendizagem, de trocas, de descobertas e de experimentação" (CUNHA, 2005, p. 77).

Observamos que a estratégia para a reintegração entre teoria e prática não está em hierarquizar uma ou outra, mas está voltada à atitude e ao planejamento do docente, como percebemos nas seguintes falas: "teoria articulada com a prática pedagógica a ser desenvolvida em sala de aula. Incentivava articulação de atividades de pesquisa" (P14); “trabalhou teoria e prática juntas, e também exemplificava como poderíamos trabalhar com os alunos" (P10).

Percebemos, também, nas colocações dos estudantes, dois entendimentos em relação à articulação teoria e prática: o primeiro expressa a aproximação da teoria com a atividade profissional, qualificando e renovando a prática educativa tanto dos alunos quanto dos docentes envolvidos; o segundo ressalta que a prática precisa estar associada à realidade, o que exige organização intencional do professor. Rays (1996, p. 40) considera que "trata-se do ato de produzir e organizar, conscientemente, os elementos socioculturais essenciais para a formação do educando", pois a separação entre teoria e prática, no processo formativo, subtrai o que é “inerente ao ser humano: sua 
integralidade biofísica e sócio-histórica" (RAYS, 1996). Em última instância, a atividade teórico-prática constitui e é constituída pelas estruturações e reestruturações da realidade objetiva e subjetiva dos sujeitos.

Assim, a relação teórico-prática precisa conter "as características de um ato científico contextualizado, evitando, assim, relações atomizadas e arbitrárias, tanto no momento de apreensão da realidade, como na objetivação das condições materiais [...]" (RAYS, 1996, p. 37). Pensar e provocar a ação historicamente situada é um dos princípios fundamentais desta relação teórico-prática. Por isto, os alunos, ao justificarem essa relação, a vincularam ao "domínio dos conteúdos", principalmente aos conteúdos de natureza procedimental.

Zabala (1998, p. 30) esclarece que “o termo 'conteúdo' normalmente foi utilizado para expressar aquilo que deve se aprender, mas em relação quase exclusiva aos conhecimentos das matérias ou disciplinas clássicas [...]”, referindo-se aos conceitos, enunciados, leis, teoremas e princípios. Neste sentido, as intenções educacionais estariam restritas à definição dos conteúdos conceituais disciplinares e ao caráter cognitivo da aprendizagem. Zabala (1998, p. 31) sugere que “[...] pensemos na maioria dos conteúdos dos exames e, concretamente, das provas de seleção - acima de tudo é preciso 'saber', que se necessita um pouco de 'saber fazer' e que não é muito necessário 'ser'[...]”, ou seja, no modelo propedêutico de ensino, têm mais importância os conteúdos de natureza conceitual do que os procedimentais e atitudinais.

Entendemos que os conteúdos conceituais expressam nossas representações do mundo e, por isto, são termos abstratos que demandam nossa compreensão. Ou será que podemos dizer que alguém aprendeu um conceito sem entender o seu significado? Para Zabala (1998, p. 43), "sabemos que faz parte do conhecimento do aluno não apenas quando este é capaz de repetir sua definição, mas quando sabe utilizá-lo para interpretação, compreensão ou exposição de um fenômeno ou situação [...]”. Assim, as condições para a aprendizagem de conceitos demandam atividades que provoquem a elaboração e a (des)construção pessoal dos conceitos e, por isto, também estão vinculados às diferentes metodologias e ao ensino de conteúdos de natureza procedimental, conforme destacado pelos estudantes. 
Acreditamos que, quando os participantes da pesquisa expressaram que o professor "entende tanto da parte histórica quanto da parte teórica” (F2); "explica de forma dinâmica, porém conceitual os processos de ensino e aprendizagem da matemática nos anos iniciais" ( $\left(\mathrm{P}_{3}\right)$, estão se referindo às atividades que contribuem para a compreensão e utilização dos conceitos, ou seja, vinculavam, também, aos conteúdos de natureza procedimental: “incentivava articulação de atividades de pesquisa” (P14), “exemplificava como poderíamos trabalhar com os alunos" (P10); "mostrava novas metodologias de ensino" (F1), etc. Trata-se de contribuir com a construção de conteúdos conceituais, procedimentais e atitudinais, de modo a desenvolver competências profissionais para expressá-los e usá-los.

Zabalza (2004, p. 200) salienta o fato de que, "com frequência, estamos muito mais envolvidos com o trabalho sobre os conhecimentos do que com as atividades sobre as capacidades vinculadas ao seu uso". Queremos que os estudantes compreendam, interpretem e recontextualizem um texto, mas não lhes ensinamos como fazê-los (afinal, são adultos!), queremos que construam um mapa conceitual, mas não os auxiliamos no desenvolvimento das habilidades necessárias para tal empreitada. Pozo (2002, p. 228) salienta que os estudantes queixam-se de que "[...] a formação é muito teórica e pouco prática. Os mestres, de que os aprendizes não sabem aplicar o que, tão claramente, lhes é explicado. Entre o saber dizer e o saber fazer há um salto que não podemos deixar que o aprendiz dê sozinho".

Nesta perspectiva, o ensino de procedimentos também foi destacado pelos estudantes que participaram da pesquisa. Pozo (2002, p. 228) considera que os conteúdos de natureza procedimental apresentam maior complexidade "já que consistem em sequências integradas de ações que vão requerer condições práticas mais exigentes para sua aprendizagem, tanto em quantidade de prática como na organização da mesma". Ou seja, implicam em saber fazer algo em direção a uma finalidade, "saber como", e não apenas saber dizer, "saber que", ou seja, utilizando-se de técnicas e de estratégias.

As técnicas podem ser consideradas como rotinas de ação automatizadas e costumam ser ensinadas por meio da apresentação de algumas instruções ou modelos de ação. As instruções, além de expressarem as finalidades para a qual se orienta o 
procedimento, especificam a sequência de passos e as ações que precisam ser realizadas. Assim, por exemplo, quando os estudantes resolvem uma dezena de exercícios de estequiometria, o fazem a partir da apresentação de algumas instruções verbais ou modelos, realizando a prática da sequência apresentada. O objetivo deste conjunto de atividades é de "consensar e automatizar a sequência de ações numa técnica ou rotina sobreaprendida" (POZO, 2002, p. 232), transformando o conhecimento explícito em um conhecimento implícito. Para esta aprendizagem, é fundamental a intervenção do professor, mediando e supervisionando o exercício da prática, regulando a aprendizagem dos procedimentos.

Uma vez aprendida a técnica, faz-se necessário o aperfeiçoamento e a transferência para diferentes situações, proporcionando a reflexão sobre as condições de uso da técnica, ou seja, a compreensão de quando, como e por que usar esta e não outra técnica. Parece-nos, contudo, que as técnicas podem ser suficientes, quando utilizadas em condições muito estáveis e preestabelecidas e, no caso da profissão docente, são requeridos dos professores processos de adaptação e o uso estratégico de procedimentos, pois a organização do sistema didático é permeada por ordem, desordem e incertezas.

As estratégias diferem das técnicas, mas são precedidas por estas e, por serem controladas e não apenas automatizadas, demandando planejamento e controle da ação. Exigem a tomada de consciência sobre a ação, mobilizando seletivamente os próprios recursos e capacidades disponíveis no repertório aprendido. Ou seja, o professor precisa dispor de um repertório de procedimentos, técnicas e habilidades, entre as quais decide utilizar, em função das demandas contextuais, aquelas que considerar mais adequadas. Por isto, a aprendizagem de procedimentos é fundamental para a formação profissional, instrumentalizando os alunos não apenas a "falar sobre" e a executar, mas saber decidir e avaliar estrategicamente as ações.

As estratégias de organização dos processos de ensino-aprendizagem foram as mais recorrentes na expressão da compreensão dos estudantes acerca das inovações no ensino. Sendo destacadas pelos estudantes como "diferentes metodologias", referindose à realização e ao uso de "pesquisas, saídas de campo, jogos, atividades diferentes e interdisciplinares" (P5); “trouxe o teatro como uma maneira diferente de trabalhar" (P8); 
“proporciona práticas, através de seminários, trocas, vivências com o assunto estudado $\mathrm{x}$ práticas [...] atividades lúdicas e na utilização das diversas modalidades tecnológicas, fazendo com que a aula possa ter um tom interessante e motivador" (P18); "uso da internet com relação às atividades, atividades experimentais" (F4); "utilização de música" (F6); "uso do moodle, aulas em laboratório, diferentes linguagens e incentivo à pesquisa" (P13); "experimentos em sala de aula e vídeos"; "construção de modelos" (B9); e de “material didático" (B10).

A maneira de organizar as sequências das atividades de aprendizagem foi percebida como uma das ações mais marcantes do ensino inovador. Nas diversas estratégias citadas pelos estudantes, observa-se a demanda de ação, de autonomia e de participação deles no trabalho a ser realizado, ou seja, as ações que realizam são fundamentais para a (des)construção dos conceitos e para a tomada de consciência acerca das dimensões da formação profissional.

Nesta perspectiva, entendemos que as diferentes metodologias proporcionam condições de organização dos esquemas de conhecimento dos estudantes, ao contemplarem momentos de equilíbrio, desequilíbrio e reequilibração. Para Zabala (2002, p. 102) “[...] a situação de aprendizagem pode ser conceitualizada como um processo de contraste, revisão e construção de esquemas de conhecimentos sobre os conteúdos [...]”. Ou seja, não basta colocar os estudantes em contato com os conteúdos de ensino. É necessário criar condições, por meio de diferentes estratégias, para reorganizarem seus esquemas de conhecimento, proporcionando situações de assimilação, desequilíbrio e acomodação de novos esquemas. Por isso, em um processo de ensino inovador, o conhecimento é proveniente das interações entre sujeito e objeto, promovendo a construção de estruturas de pensamento.

Consideramos que as diferentes metodologias, para além de uma escolha técnica, incluem certas atividades, determinadas interações e situações comunicativas entre alunos e professor, formas de organização social da turma, organização dos conteúdos e dos materiais curriculares, bem como da avaliação (ZABALA, 1998). Estas dimensões são variáveis e podem expressar maior ou menor significado para o grupo, dependendo das suas experiências e expectativas formativas, mas expressam os pressupostos epistemológicos e a concepção de aprendizagem subjacente à prática educativa. 
Alguns pronunciamentos dos estudantes evidenciaram como inovador a contextualização dos conteúdos de ensino, destacando duas perspectivas de contextualização. A primeira, ao se reportarem ao trabalho com questões atuais em aula como nas seguintes falas: "em aulas foram discutidas pesquisas e cientistas atuais, o que estão realizando e no que estão buscando com suas experiências, nos situando no que os conteúdos apresentados estão relacionados com as pesquisas atuais" (F4); "atividades propostas (...) que aproximam da realidade que iremos enfrentar ao nos formarmos" (F1). A segunda considera a contextualização, quando o professor relaciona o conteúdo científico com o cotidiano em que os alunos estão inseridos. Esse exemplo, "valorizava a articulação entre os saberes do cotidiano, os científicos, teoria e prática" (F4), "uma aposta didática interessante centrada na escrita, no diálogo e na leitura. Onde busca trabalhar com aspectos pertinentes ao cotidiano dos alunos" (Q8).

A contextualização, a partir desses dois olhares, inscreve-se em "[...] uma opção radical em relação aos programas de conteúdo, com valorização do contexto desde o início do processo não apenas tentando fazer aproximações no fechamento dos estudos" (MORAES, 2008, p. 21). É compreendido através das falas que,

o cotidiano das pessoas, o seu contexto, pode ser concebido como a linguagem e o discurso que dominam. Por isso um currículo efetivamente contextualizado precisa partir do que os alunos conseguem falar e expressar sobre o mundo, visando uma apropriação cada vez mais complexa dos discursos em que estão inseridos, incluindo-se nisso excursões em outros discursos, especialmente o da ciência. (MORAES, 2008, p. 20)

Portanto, se o contexto é discurso e se o discurso se transforma por meio do movimento de seu contexto original para um contexto modificado, pontuamos que o discurso pedagógico transita entre a prática e o contexto, deslocando-se e realocando entre essas produções discursivas. Ou seja, o professor, em meio a essa transição, cria, em seu discurso pedagógico, um sujeito imaginário e precisa organizar através de situações cotidianas os discursos e linguagens já conhecidos pelos alunos, visando sua complexificação (MORAES, 2008) e, para Bernstein (1996), esse processo não é rápido e necessita ser refinado, recontextualizado. 
Para Bernstein (1996, p. 259), o princípio recontextualizador "seletivamente, apropria, reloca, refocaliza e relaciona outros discursos, para constituir sua própria ordem e seus próprios ordenamentos". O discurso é sempre transformado e não segue uma normatividade, pois os conteúdos, primeiramente trabalhados em aula, são inseridos em outros contextos que condicionam reinterpretações, releituras e alterações nos significados. O professor que sustenta um discurso próprio e que não o coloca em uma relação mútua com outros saberes, incluindo o dos estudantes, condiciona seu discurso a uma linearidade, negando as possibilidades de sua recontextualização em meio aos diferentes estudantes e contextos envolvidos, o que justifica as considerações dos estudantes de que a contextualização expressa uma ação inovadora.

A contextualização também movimenta a curiosidade epistemológica dos alunos, que destacaram a pesquisa como uma ação inovadora. Percebemos, nas falas dos alunos, quatro dimensões da pesquisa em sala de aula: a) como produção escrita; b) como apropriação do conhecimento científico; c) como procedimento e atitude de pesquisar; e d) como reflexão sobre o processo de pesquisa. Estas dimensões estão imbricadas na dinâmica interativa da ação educativa, conforme enunciado nas falas a seguir: "[...] traz pesquisas, exemplos do cotidiano, saída de campo [...] realizou diferentes atividades, seja de pesquisa, entrevista, experiências" (P5) e "articulação com a realidade vivida, exemplos do cotidiano e incentivo à leitura, à pesquisa e à escrita crítica" (P11).

Articulada com a categoria da contextualização, destacamos mais uma ação inovadora percebida pelos alunos: a problematização. Consideramos que esta se vincula à condição reflexiva que perpassa as ações educativas e, também, fomenta, a partir do contexto do aluno, a discussão de questões desafiadoras, visando problematizá-las para que os conceitos científicos sejam melhor compreendidos e ressignificados (FREIRE, 1996; DELIZOICOV, ANGOTTI, PERNAMBUCO, 2011).

Para os estudantes, uma aula problematizadora é aquela que "promove a crítica, o questionamento dentro de um grupo com várias perspectivas quanto ao modelo de sociedade" (P22), bem como uma "aula com muitos debates e discussões e nos faz refletir sobre o ato de lecionar de maneira mais aberta e inteligente" (P17). O aprender, por via problematizadora, envolve o diálogo e o reconhecimento, do professor, de que o aluno possui saberes e que esses necessitam ser partilhados com o grupo que constitui a 
aula, estabelecendo uma integração dos saberes. O ingrediente inovador não está, simplesmente, em realizar um conjunto de questionamentos sobre o tema em estudo. $\mathrm{O}$ que promove a problematização, como ação inovadora, é a intencionalidade do professor para que a discussão não seja incipiente, mas, que incite a curiosidade epistemológica dos alunos, o querer saber mais (FREIRE, 1996).

O procedimento pedagógico nessa concepção mobiliza professor e aluno a questionar a si próprios e aos outros, como observado nas falas subsequentes dos estudantes: "seus questionamentos em aula nos fazia pensar (analisar)" (B2); “[...] porque é um professor que questiona, e também traz a prática para a sala de aula, e trabalha também o lúdico" (P16). Entendemos, pelas falas, que a mediação do professor está em promover essa interlocução de saberes, com o intuito de ampliar a capacidade de argumentação e a reflexão dos alunos, auxiliando-os no desenvolvimento de atitudes questionadoras diante dos processos de ensino-aprendizagem.

A problematização mobiliza os estudantes para a elaboração de questionamentos e formulação de pressupostos que podem envolver explicações sobre os processos pelos quais chegaram a tais conhecimentos, empregando a linguagem para a partilha, a contextualização e a recontextualização das experiências vividas.

Ancoradas, também, nesse entendimento, destacam-se as manifestações dos estudantes referentes à interdisciplinaridade, pois expressaram que o professor promovia inovações no ensino ao desenvolver "atividades diferentes e interdisciplinares" (P5); “relacionava a psicologia com a química na forma de apresentação de seminários da área" (Q8). Acreditamos, na interdisciplinaridade, como possibilidade inicial de articulação disciplinar, uma vez que direciona para uma reintegração dos saberes que constituem a formação dos licenciandos.

Masetto (2010, p. 60) destaca que o conhecimento, demandado pela sociedade contemporânea, é aquele que "abre-se para outras ciências e formas de conhecimento, procura integração, diálogo, complementação para melhor compreender o que está acontecendo no mundo e com a humanidade e seus fenômenos de múltipla causalidade".

Nossos entendimentos não negam a importância do conhecimento disciplinar, mas denunciam sua limitação e propõem a reintegração dos saberes. Compreendemos 
que a supremacia da disciplinariedade ampliou os conhecimentos específicos de que hoje desfrutamos, como o desenvolvimento das ciências e da tecnologia, mas seguindo um raciocínio cartesiano de objetividade, linearidade e descontextualização, separou o homem da natureza, os homens da humanidade, o conhecimento da vida. Parafraseando Morin (2008), o desafio não é apenas modernizar a cultura, mas, também, “culturalizar a modernidade". Por meio de atividades interdisciplinares ou que fomentem o pensamento interdisciplinar, os alunos podem desenvolver a capacidade de transferir habilidades, conhecimentos e atitudes de um contexto para o outro, entender diferentes pontos de vista e, principalmente, desenvolver uma atitude epistemológica reintegradora.

O processo de (re)organização do conhecimento necessita permear todo o percurso formativo do licenciando. Assim, a universidade é responsável, por meio de seus cursos de graduação, por oportunizar diferentes vivências e situações de ensino, de pesquisa e de extensão que incentivem a ressignificação, o reconhecimento dos diferentes saberes, tácitos ou não, convidando e incentivando o estudante a pensar sobre a própria construção do conhecimento. Isso contribui para a construção e reorganização do conhecimento.

Logo, o educar pela pesquisa também contribui significativamente para uma mudança na formação inicial dos professores, pois possibilita que a sala de aula constituase como um lugar de aproximação do ensino e da pesquisa, incidindo na constituição do aluno, não como reprodutor de estudos científicos, mas como produtor desse processo (GALIAZZI, 2003). Assim, expõe o aluno (P11), que considera a "articulação com a realidade vivida, exemplos do cotidiano e incentivo à leitura, à pesquisa e à escrita crítica". O inovador da pesquisa em aula se expressa na possibilidade de desenvolvimento da autonomia do sujeito aprendente, bem como no reconhecimento da capacidade de investigação e de produção (escrita, oral, artística) desse estudante universitário.

Encontramos em Demo (1997) a afirmação de que a pesquisa é uma maneira própria de aprender. Para esse autor, ao educar pela pesquisa, o professor reconhece o aluno não como objeto, mas como um colaborador no processo de aprendizagem. Neste sentido, a atitude de pesquisar e refletir sobre a pesquisa como atividade cotidiana, em aula, incentiva o aluno não apenas a construir o conhecimento como também a 
reconstruí-lo, sendo o último um elemento-chave para a aquisição de conhecimento (DEMO 1997; MORAES, 2004).

A pesquisa em sala de aula pode oportunizar o "desenvolvimento da autonomia intelectual, da consciência crítica" (DEMO, 1997, p. 86) promovendo a aquisição de posturas questionadoras e curiosas. Com isso, o estudante tem acesso a diferentes pesquisas, ou seja, a conhecimentos novos, que ao serem trabalhados como princípio educativo têm seus resultados reconstruídos através de leitura e interpretação críticas dos estudantes; atividades assim otimizam processos de "[...] interpretação própria, formulação pessoal, elaboração trabalhada, saber pensar, aprender a aprender" (DEMO, 1997, p. 11).

Compreendemos que o processo de formação inicial de professores, acompanhado pela vivência em pesquisa, torna-se inovador com relação a dois pontos: primeiro, porque conduz ao saber pensar, escrever, analisar e refletir; segundo, porque o educar pela pesquisa está na contramão de uma perspectiva tradicional de ensino. $O$ aprender, aqui, assume outra definição: ao invés de aprender memorizando, o aluno passa a aprender com significado (DEMO, 1997).

Este aprender com significado situa-se no plano afetivo que perpassa as relações didáticas. Por isso, as relações interpessoais entre professor e aluno também foram anunciadas como inovações no ensino. A este respeito, Hassenforder (1974, p. 85) analisa que

[...] os êxitos registrados nas experiências pedagógicas são, em grande parte, devidos à motivação superior dos professores e alunos. [...] o entusiasmo dos professores, manifestado pelo seu brilho, pelo seu esforço e pela competência assim adquirida, pode ter efeitos extremamente benéficos.

Corroborando com o autor, os estudantes expressam o significado inovador dessas interações: “[...] considera os saberes dos alunos, valoriza, respeita e se mostra aprendiz junto com os alunos [...] valoriza os saberes, estimula o aluno a buscar além do conhecimento que possui, mas não minimiza ninguém” (P15); “[...] grande respeito com 
seus alunos, este professor consegue trazer os alunos para o seu conteúdo apenas com o giz e quadro negro" (B1).

Percebemos, também, o quanto o respeito permeia essas falas. Mas este não seria um princípio que perpassa toda a prática educativa? Seria, mas não se faz presente em todas as relações pedagógicas vivenciadas por esses estudantes, o que é preocupante. $\mathrm{O}$ distanciamento entre professores e alunos pode resultar em um conjunto de incompreensões.

Deste modo, o diálogo, o incentivo, o modo de conduzir a aula e as próprias expressões faciais do professor são observados e interpretados pelos alunos como parte da ação do docente. É claro que não queremos dizer, com isto, que o professor deve ser sorridente e simpático, mas que é essencial manter uma relação respeitosa e próxima dos estudantes. Sobre isto, Santos (2010, p. 35) afere que "[...] ao estabelecer relações com os alunos, o professor ativa todo o seu conceitual intelectual e emocional, trazendo à tona suas capacidades, qualidades, limitações e contradições".

Assim, a relação vincular entre professor e aluno gera maior aprendizagem. De certa maneira, o aluno se refere ao professor com mais cuidado o que, consequentemente, faz com que ele se envolva mais com a aula e, com isso, a situação de ensino se torna mais prazerosa e interessante. A interação objeto-aluno é geradora de conhecimento, todavia a interação professor-aluno além do conhecimento potencializa um ambiente de ensino afetuoso.

Sendo assim, compreendemos que a inovação anunciada pelos alunos está na opção do professor em colocar-se no caminho da humanização das relações humanas. Ou seja, o professor necessita reconhecer e estreitar as relações entre a inteligência e a afetividade, pois o homem racional é também emocional (MORIN, 2000). Essa compreensão contribui para a constituição de um clima permissivo e positivo em sala de aula, uma vez que o aprendizado é, também, mobilizado pelos sentimentos, sensações e emoções. 


\section{Considerações finais: das inovações no ensino ao ensino inovador}

Afinal, que compreensões se organizaram a partir dos anúncios dos estudantes sobre as inovações no ensino?

Primeiramente, entre as inovações anunciadas pelos estudantes, nos parecem basilares a representação que construímos sobre todo e qualquer processo de ensino. Então, por que são consideradas inovações no ensino? Para responder a esta questão, precisamos considerar que o que denominamos ensino possui elementos básicos que o estruturam como um sistema, neste caso, um sistema didático: alunos, professores, conteúdos e contexto (tempo e espaço). Este sistema não é fechado e nem decomponível, ou seja, não podemos isolar as partes e modificá-las de forma independente umas das outras, pois o processo de ensino é constituído pela confluência de elementos interdefinidos. Logo, são as mudanças nas interações entre os elementos que promovem as inovações.

Precisamos considerar, então, o sistema didático como uma organização complexa, pois como bem define Morin (2008, p. 272), "a complexidade não está na bruma fenomenal do real. Está no seu próprio princípio”. Encontramos na complexidade uma teoria paradigmática que "não é o fim do conhecimento, mas um meio-fim inscrito em permanente recorrência" (MORIN, 2008, p. 336), pois o ensino inovador, que é de natureza complexa, só se sustenta à custa de uma recriação permanente do pensamento.

Inovação é movimento e, por isto, processo que não pode ser simplificado a uma degradação tecnicista, como se as inovações no ensino fossem generalizáveis, enxertadas ou aplicadas a partir do que pode ser operacional em uma teoria. Também não pode ser vulgarizada e difundida à custa da criação de necessidades de consumo e modernização, nem tornar-se doutrinária, abafando as contradições, as diferenças e as contestações que emergem das interações.

As inovações no ensino, em nosso entendimento, potencializam o movimento de organização de um ensino inovador que, de forma retroativa, só se sustentará com a reorganização e reestruturação de inovações permanentes. Ou seja, as inovações no ensino situam-se no eixo estratégico potencializando alterações incrementais, pontuais e aleatórias no ensino. Por sua vez, o ensino inovador altera o modo de compreender a 
organização do conhecimento, por isso sua vinculação ao eixo epistemológico, uma vez que anuncia ruptura e mudança no ensino. Conforme apresenta a figura abaixo:

Figura 1 - Retroações na organização de um ensino inovador

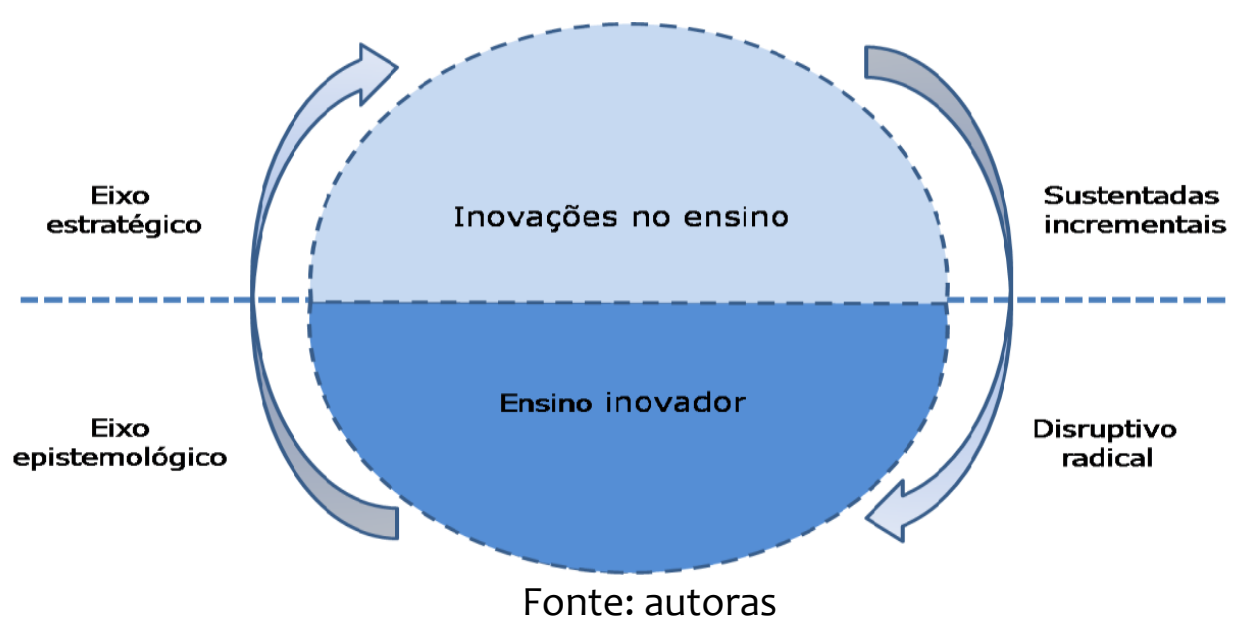

Nesta perspectiva, passamos a considerar as inovações no ensino como as relações que alteram a organização do sistema didático. Consideramos sistema (GARCíA, 2002; MORIN, 2008) como uma representação que pode ser compreendida e analisada como uma totalidade organizada, ou seja, possuindo um conjunto de atividades como resultado da coordenação das ações desempenhadas pelas suas partes constitutivas.

No sistema didático em questão, considerado como um sistema complexo e, por isto, aberto, os elementos não são estáticos, mas "flutuam permanentemente sob a influência de elementos que ficaram 'fora do sistema' e que chamarei de 'condições de contorno dos sistemas" (GARCíA, 2002, p. 62). As flutuações destes elementos podem, em pequena escala, introduzir mudanças, mas não alterar as relações fundamentais da organização didática. É o caso das inovações no ensino. Contudo, quando estas flutuações são mais intensas, ou poderíamos dizer que, quando as relações, interações e retroações modificam as propriedades e as atividades dos elementos, pode ocorrer uma mudança na organização do sistema didático. Esta ordem e desordem, por conseguinte, pode levar à construção permanente de um ensino inovador. 
Figura 2 - Sistema didático do ensino inovador na perspectiva da complexidade (inspirado em MORIN, 2008)

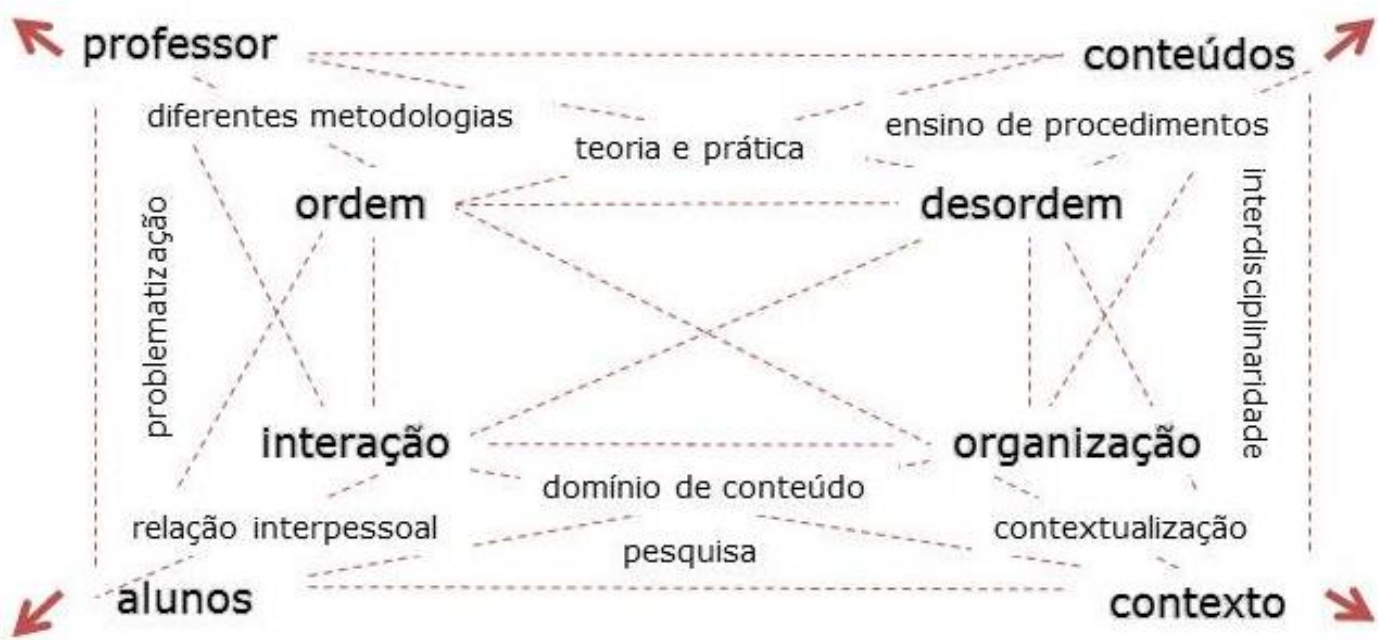

Fonte: autoras

O sistema didático, onde se organiza o ensino inovador, é constituído por processos de codeterminação entre os elementos que o constituem, de tal forma que não se pode separá-los. Por isto, nosso estudo, que pretende a compreensão das possibilidades de um ensino universitário inovador, dedicou-se, neste momento, a abordar a perspectiva dos estudantes. Na sequência da pesquisa, os demais elementos serão investigados, pois estão interdefinidos. É inegável, portanto, que cada estudo expresse as relações entre uma quantidade limitada de elementos abstraídos do complexo e que nossa construção conceitual representa o que consideramos mais significativo no complexo empírico do ensino.

As inovações, aqui anunciadas, são advindas das experiências formativas positivas dos estudantes, que expressam, em seus discursos, as percepções sobre as diferentes e alternativas formas de ensino. Essas inovações podem não ser radicais ou desencadeadoras de mudanças, mas, algumas, alertam sobre a necessidade de superação de discursos e ações cristalizadas, como, por exemplo, a dicotomia teoria-prática.

Evidencia-se que as práticas modelizadoras e reguladoras não dão conta da subjetividade e das complexas interações vivenciadas no espaço educativo. As categorias que emergiram da pesquisa, tais como diferentes metodologias, contextualização e relações interpessoais elucidam este entendimento. 
É importante destacar que as novas tecnologias na educação não emergiram como uma atividade inovadora e, sim, como uma possibilidade dentro da categoria diferentes metodologias. Grande número de pesquisas (MASETTO, 2010.) consideram a tecnologia como grande vetor da inovação. Em nosso contexto, ela faz parte dos recursos de ensino e aprendizagem, ou seja, fazer uso de recursos tecnológicos não assegura uma ação educativa diferenciada.

Percebemos, também, que as inovações no ensino não representam uma ruptura epistemológica, mas redimensionam um fazer diferente, que pode ou não proporcionar alterações na ação docente. Ou seja, as inovações pontuais no ensino não garantem uma transição paradigmática, mas anunciam as possibilidades de um ensino inovador.

Assim, a perspectiva da complexidade nos auxilia nessa compreensão, uma vez que ela nos permite leituras plurais dos fenômenos complexos, visando à heterogeneidade das partes, sem desconsiderar a temporalidade do todo. Por fim, cabenos ressaltar, ainda, que os sentidos e significados dos processos didáticos inovadores encontram-se na singularidade e na pluralidade da própria experiência educativa, pois processos não lineares, ou seja, o atributo inovador não é um fim do ensino, mas um processo em movimento constante e contínuo.

\section{Referências}

BARDIN, Laurence. Análise de conteúdo. Tradução de Luís Antero Reto e Augusto Pinheiro. Lisboa: Edições, 1977.

BERNSTEIN, Basil. A estruturação do discurso pedagógico: classe, códigos e controle. Vozes: Petrópolis, 1996. 
CARBONELL, Jaime. A aventura de inovar: a mudança na escola. Porto Alegre: Artmed, 2002.

CHRISTENSEN, Clayton; HORN, Michael; JOHNSON, Curtes. Inovação na sala de aula: como a inovação de ruptura muda a forma de aprender. Porto Alegre: Bookman, 2012.

CUNHA Maria Isabel da. Sala de aula: espaço de inovações e formação docente. In: ENRICONE, Délcia, GRILLO Marilene, (Eds.), Educação superior: vivências e visão de futuro. Porto Alegre: EDIPUCRS, 2005. p. 71-82.

DELIZOICOV, Demétrio; ANGOTTI, José André; PERNAMBUCO, Marta Maria. Ensino de ciências: fundamentos e métodos. São Paulo: Cortez, 2011.

DEMO, Pedro. Educar pela pesquisa. Campinas, SP: Autores Associados, 1997.

FARIAS, Isabel Maria Sabino. Inovação, mudança e cultura docente. Brasília: Líber livro, 2006.

FREIRE, Paulo. Pedagogia da autonomia: saberes necessários à prática educativa. São Paulo: Paz e Terra, 1996.

GALIAZZI, Maria do Carmo. Educar pela pesquisa: ambiente de formação de professores de ciências. Ijuí: Ed Unijuí, 2003.

GARCÍA, Rolando. O conhecimento em construção: das formulações de Jean Piaget à teoria dos sistemas complexos. Porto Alegre: Artmed, 2002.

HASSENFORDER, Jean. A inovação do ensino. Lisboa: Livros horizonte, 1974.

KRASILCHIK, Miriam. Inovação no ensino de ciências. In: GARCIA, Walter. Inovação educacional no Brasil. São Paulo: Cortez, 1980. p. 164-184.

MASETTO, Marcos Tarciso. O professor na hora da verdade: a prática docente no ensino superior. São Paulo: Avercamp, 2010.

MORAES, Roque. (Org.). Pesquisa em sala de aula: fundamentos e pressupostos. In: MORAES, Roque; LIMA, Valderez Marina do Rosário. (Eds.). Pesquisa em sala de aula: tendências para a educação em novos tempos. $2^{\text {a }}$ Edição- Porto Alegre: EDIPUCRS, 2004. p. 9-23.

MORAES, Roque. Cotidiano no ensino de química: superações necessárias. In: GALIAZZI Maria do Carmo. (Ed.). Aprender em rede na educação e ciências. Ijuí, RS. Ed. Unijuí, 2008. p. 15-34.

MORIN, Edgar. Os sete saberes necessários à educação do futuro. $2^{\mathrm{a}}$ ed. São Paulo: Cortez; Brasília, DF: UNESCO, 2000. 


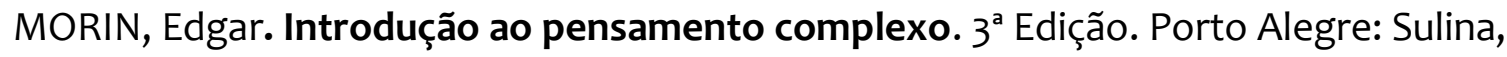
2007.

MORIN, Edgar. Ciência com consciência. 11ª Edição. Rio de Janeiro: Bertrand Brasil, 2008.

PIMENTA, Selma Garrido. (Ed.). Saberes pedagógicos e atividade docente. São Paulo:

Cortez, 1999.

POZO, Juan Ignacio. Aprendizes e mestres: A nova cultura da aprendizagem. Porto Alegre: Artmed, 2002.

RAYS, Oswaldo Alonso. A relação teoria-prática na didática escolar crítica. In: VEIGA, Ilma

Passos Didática: O ensino e suas relações. Campinas, SP: Papirus, 1996. p. 33-52.

SANTOS, Akiko. Didática sob a ótica do pensamento complexo. $2^{\mathrm{a}}$ ed. Porto Alegre:

Sulina, 2010.

SANTOS, Akiko; SOMMERMAN, Américo. Complexidade e transdisciplinaridade: em busca da totalidade perdida. Porto Alegre: Sulina, 2009.

SILVA, Edileuza Fernandes. Nove aulas inovadoras na universidade. Campinas, SP: Papirus, 2011.

TRIVIÑOS, Augusto Nibaldo. Introdução à pesquisa em ciências sociais: a pesquisa qualitativa em educação. São Paulo: Atlas, 1987.

ZABALA, Antonio. A prática educativa: como ensinar. Porto Alegre: Artes Médicas, 1998.

ZABALA, Antonio. Enfoque globalizador e pensamento complexo: uma proposta para o currículo escolar. Porto Alegre: Artmed 2002.

ZABALZA, Miguel. 0 ensino universitário: seu cenário e seus protagonistas. Porto Alegre: Artmed, 2004.

Universidade do Estado de Santa Catarina - UDESC Programa de Pós-Graduação em Educação - PPGE

Revista Linhas

Volume 19 - Número 39 - Ano 2018

revistalinhas@gmail.com 